\title{
Analysis of Electrochemical Corrosion in Metal form of Ti-Ta-Sn and 316-L Screw in Hank's Solution by SEM
}

Abraham Mejia ${ }^{1}$, Luis Bejar Gómez ${ }^{2}$, Claudio Aguilar ${ }^{3}$, Andres Bejar ${ }^{1}$, Carolina Parra González ${ }^{4}$ and Guillermo Carreón ${ }^{1}$

${ }^{1}$ Universidad Michoacan de San Nicolas de Hidalgo, Michoacan de Ocampo, Mexico, ${ }^{2}$ Universidad Michoacana de San Nicolás de Hidalgo, Michoacan de Ocampo, Mexico, ${ }^{3}$ Universidad Técnica Federico Santa Maria, Valparaíso, Valparaiso, Chile, ${ }^{4}$ Universidad Técnica Federico Santa María, Valparaiso, Chile

The most widely used alloys are Ti-6Al-4Vn, Ti Grade 4, 316-L, due to their excellent mechanical properties and resistance to corrosion. The use of titanium in biomedical applications has been considered one of the most used metallic materials in the restoration of tissues and replacement of bone implants. In this article, the corrosion effects of the Ti-Ta-Sn alloy were studied in order to improve the electrochemical properties of some previously studied and existing biomaterials [1-3]. However, poor wear resistance and hardness of Ti are two drawbacks of its application. Outstanding mechanical and chemical properties of Ti including high strength to weight ratio, light weight, high melting point,

corrosion resistance, and biocompatibility make it a backbone material in industry [4]. Where the morphology and composition of the coatings obtained by means of scanning electron microscopy (SEM) was studied. The electrochemical study was carried out in a cell with 3 electrodes in Hank's solution at 37 ${ }^{\circ}$ C. SEM was subsequently carried out where a morphology with shades of gray is observed in the micrographs, presenting an excellent homogeneous alloy. The results show that the temperature and the $\mathrm{pH}$ value of the solution had an obvious effect on the microstructure of the Ti-Ta-Sn alloy and on the coating of the 316-L screw. The corrosion in the piece 316-L only presented uplift in the form of layers, in the Ti-Ta-Sn alloy there are cracks and bubble-shaped pits. When the $\mathrm{pH}$ value of the solution is high, the microcracks become relatively smaller. Therefore, the high $\mathrm{pH}$ value of the solution increases the compactness of the coatings. The greater compactness of the coatings favors the improvement of the corrosion resistance. The study of electrochemical corrosion, in general, displayed good stability in the passive state, which improves corrosion resistance. Both samples were prepared at $37^{\circ} \mathrm{C}$ with a pH value of 6.5. We conclude that the Ti-Ta-Sn alloy in comparison with the commercial material 316-L presents an excellent behavior as a biomaterial, taking into account the passivation of the corrosion resistance [1]. 


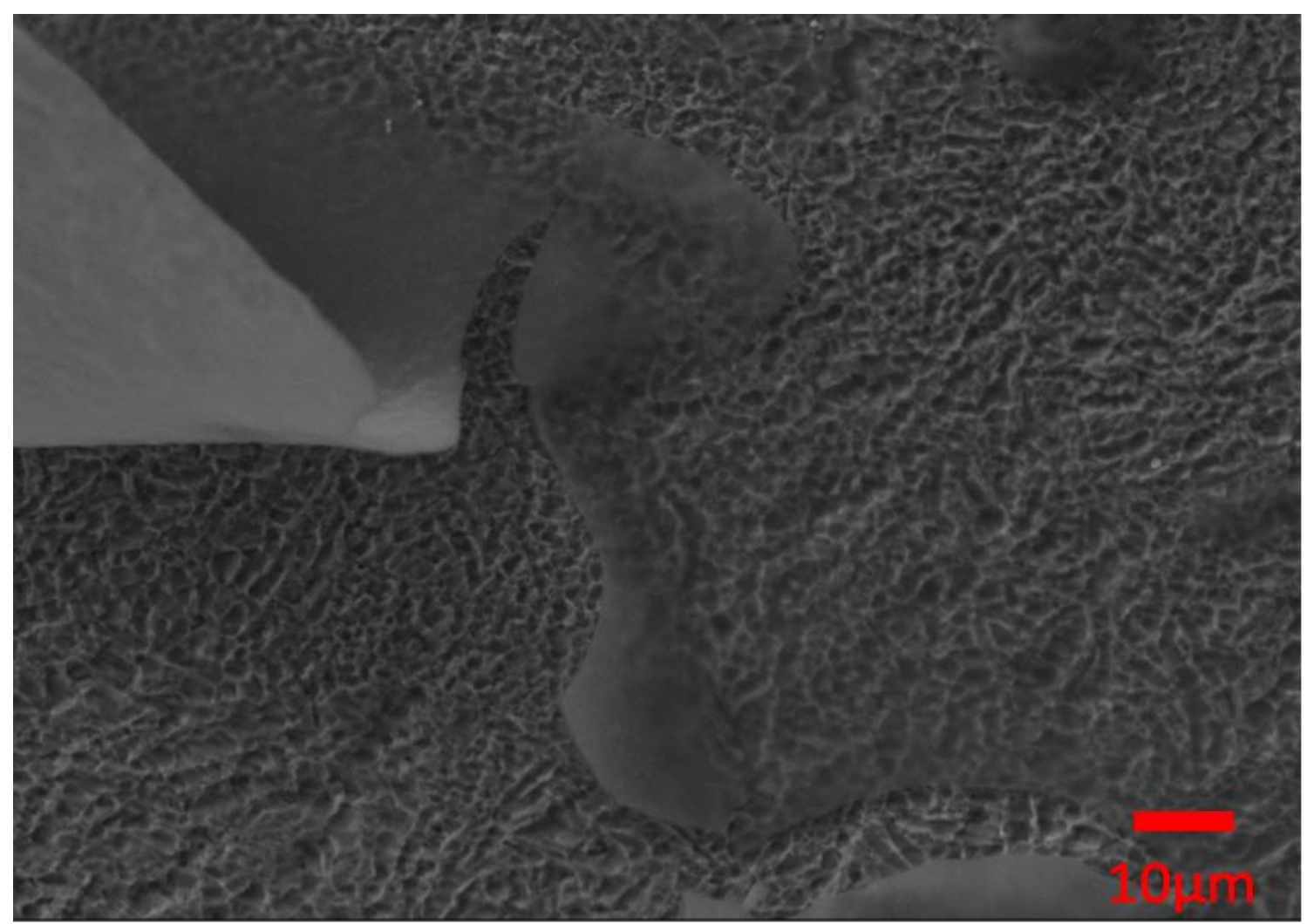

Figure 1. Fig. 1. Morphology of the 316-L coatings prepared in the solutions at temperature $37^{\circ} \mathrm{C}$.

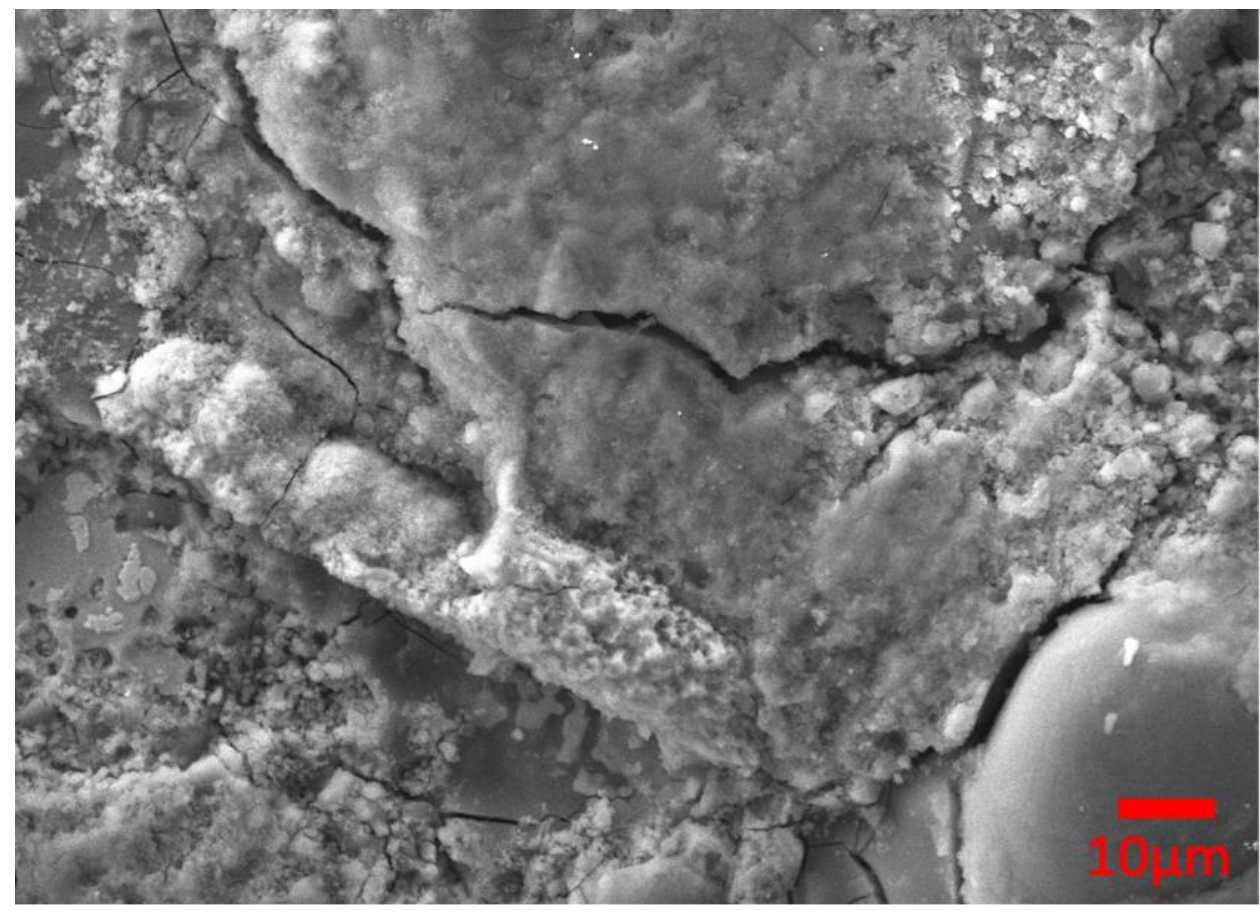

Figure 2. Fig. 2. Morphology of the alloys Ti-Ta-Sn without coatings prepared in the solutions at temperature, $37^{\circ} \mathrm{C}$. 


\section{References}

[1] Junfeng Gou, Mingren Sun, Xinxin Ma, Guangze Tang, Yongkang Zhang Effects of temperature and pH value on the morphology and corrosion resistance of titanium-containing conversion coating, Applied Surface Science Advances 3 (2021) 100060 p.1-10.

[2] Mohazzab, B. F., Jaleh, B., Fattah-alhosseini, A., Mahmoudi, F., \& Momeni, A. (2020). Laser surface treatment of pure titanium: Microstructural analysis, wear properties, and corrosion behavior of titanium carbide coatings in Hank's physiological solution. Surfaces and Interfaces, 100597. doi:10.1016/j.surfin.2020.100597

[3] I. Pohrelyuk, V. Fedirko, O. Tkachuk, R. Proskurnyak, Corrosion resistance of Ti-6Al-4V alloy with nitride coatings in Ringer's solution, Corros. Sci. 66 (2013) 392-398, https://doi.org/10.1016/j.corsci.2012.10.005.

[4] Y. Luo, S. Ge, Z. Jin, J. Fisher, Effect of surface modification on surface properties and tribological behaviour of titanium alloys, Proc. Inst. Mech. Eng. J J. Eng. 223 (2009) 311-316, https://doi.org/10.1243/13506501JET488. 